\title{
SOME NONLINEAR TAX EFFECTS ON ASSET VALUES AND INVESTMENT DECISIONS UNDER UNCERTAINTY
}

\author{
Jeffrey K. MACKIE-MASON* \\ University of Michigan, Ann Arbor, MI 48109-1220, USA, and NBER
}

Received February 1989, revised version received December 1989

\begin{abstract}
Tax system nonlinearities are often ignored but with uncertainty may have important implications for the magnitude and direction of tax effects. This paper studies a particular nonlinear tax rule. The policy subsidizes asset values, but may discourage some investments and encourage earlier shutdown of some projects. The marginal effective tax rate varies with project risk. Furthermore, a corporate cash-flow tax can encourage investment due to interactions with the nonlinear policy. The paper also presents a general statement of the stochastic equilibrium valuation method which can be used to analyze other nonlinear taxes. Numerical examples demonstrate computational feasibility.
\end{abstract}

\section{Introduction}

The typical approach to modeling tax systems in much of the public finance literature is to treat them as symmetric and linear. Yet real-world tax systems are rife with nonlinearities, asymmetries and nondifferentiable kinks. Nonlinearities are sometimes sufficiently small that they can be well approximated by linear functions, but in other cases ignoring the nonlinearities can lead to serious errors. In particular, when nonlinearities interact with uncertainty the results of policy interventions are often quantitatively different and sometimes even change direction from predictions based on linearity and certainty.

This paper studies the effects of tax system nonlinearities in the presence of uncertainty. The crucial effect of uncertainty is to make the appropriate discount rate different for elements of cash flow with different risk characteristics, and further to make the discount rate endogenous if the firm makes any endogenous operating decisions. Section 2 presents a general statement of the 'stochastic equilibrium valuation' method for analyzing asset values and investment decisions when tax policies are nonlinear. The basic valua-

*I wish to thank Paul Courant, Jerry Hausman, Diderik Lund, Bruce Meyer, Jeff Miron, Bob Pindyck, Jim Poterba and two anonymous referees for helpful discussions and suggestions. Financial support was received from the National Science Foundation and the Alfred P. Sloan Foundation. 
tion approach is not new, but there have been only a few earlier applications to tax analysis and those have addressed limited, specific problems. I provide a concise, general statement of the stochastic equilibrium valuation method which serves as a guide to evaluating a variety of tax policies. ${ }^{1}$

In section $3 \mathrm{I}$ apply the method to analyze the U.S. percentage depletion allowance. I show that, contrary to simple intuition based on linearity and certainty, the depletion allowance can discourage investment in some projects even though it is an unambiguous subsidy to asset values. The allowance may also increase the probability that marginal projects will be shut down. Furthermore, riskier projects receive smaller subsidies so the marginal effective tax rate on asset value varies with risk class. I also show that increasing the corporate income tax rate may encourage investment, due to interactions with the nonlinear depletion allowance. Thus, the analysis in this section shows quite clearly how important it can be to account for the interactions between nonlinearities and uncertainty.

The qualitative results of section 3 are confirmed with a numerical analysis of a more realistic investment problem in section 4 . The two sections together demonstrate the feasibility of using the stochastic equilibrium valuation method for analytical and numerical investigation of nonlinear tax policies.

There are at least three reasons why nonlinearities may be important for tax studies. First, nonlinearities affect the government's share of risk in a firm's uncertain cash flows which can cause unexpected effects on asset values and investment decisions. Second, nonlinearities often make tax parameters endogenous (for example, the agent may choose to be above or below a ceiling for a subsidy) with important implications for both modeling and cconometric analysis. Third, nonlinearities may be important in policy analysis for accurate estimates of efficiency costs and incidence, particularly when uncertainty is substantial.

Other papers have investigated the importance of some nonlinearities in tax policies. For example, in addition to the papers cited above, Auerbach (1986) and Mayer (1986) both use dynamic programming models to study the asymmetric treatment of tax losses. ${ }^{2}$ However, both of those papers assume risk-neutral valuation, and thus ignore the difficulties when discount rates are endogenous and different for different elements of cash flow, as they are when shareholders are risk averse. Although the focus of my application is a percentage depletion allowance, I also model the effects of tax loss asymmetry, but allow for risk-averse shareholders.

\footnotetext{
${ }^{1}$ Ball and Bowers (1983) and Majd and Myers (1985, 1986) use similar methods to study some effects of loss carryforwards, but they do not allow firms to make any operating changes in response to tax changes. Lund (1987) studies the effects of existing Norwegian taxes on oil field investments, without considering the effect of changing tax policies.

${ }^{2}$ See also Edwards and Mayer (1983) on leasing.
} 
There is a long tradition of considering the risk-sharing effects of taxation in an uncertain world, beginning with Domar and Musgrave (1944). In that paper, the authors pointed out that by taxing a risky stream of income, the government was shifting part of the risk onto itself, which would affect the value of the income stream to a risk-averse individual. The analysis was placed in a general equilibrium framework by Gordon (1985), followed by a debate about the efficiency costs of taxes on risky assets by Bulow and Summers (1984) and Gordon and Wilson (1989). The analysis in this paper takes risk-sharing into account, and uses the stochastic equilibrium valuation method to determine the value of that risk-sharing to the firm when discount rates are endogenous and different for different risky elements of cash flow. Furthermore, this paper highlights interactions between risk-sharing and tax system nonlinearities, a topic not treated by the papers cited above.

The importance of endogeneities that result from tax nonlinearities has been illustrated, for instance, in the labor supply literature. Hausman (1981) studied the effects of the nonconvex budget schedule induced by various tax subsidies and transfers to individuals in the United States. The nonlinearities require the analyst to account for the individual's endogenous choice of which part of the budget segment to be on.

Many tax policies have kinks and nonlinearities similar to those studied here, e.g. capital loss limitations for individuals, 'passive loss' restrictions introduced by the 1986 U.S. Iax Reform Act, and foreign tax credit limitations. Linearity and certainty may sometimes be reasonable approximations, but this paper demonstrates that nonlinearities and uncertainty can be qualitatively and quantitatively important, and that feasible methods have been developed to analyze many nonlinear tax problems.

\section{Valuing risky assets and investment decisions}

In this section I present a general statement of the stochastic equilibrium method for valuing risky assets and investment decisions in the presence of nonlinear tax policies. The theory was introduced in the finance literature by Constantinides (1978). Applications in the public economics literature have been special cases which assumed that firms do not respond to tax policies. ${ }^{3}$ I allow for endogenous control decisions and thus unify the analysis of asset values and investment decisions.

Other recent studies have adopted variants of the valuation method to study asset values or managerial decisions without studying tax effects. Notable examples are McDonald and Siegel (1986) on delaying investment

\footnotetext{
${ }^{3}$ See the references in footnote 1 .
} 
decisions, Brennan and Schwartz (1986) on valuing mining projects, ${ }^{4}$ and Paddock, Siegel and Smith (1988) on valuing offshore petroleum leases.

A general description of the procedure follows. Suppose we wish to value an asset or project whose value depends on some exogenous random variables evolving over time (such as output price) and some economic decision variables the firm will be able to control (such as output). Analyzing investment decisions will be a special case of the general valuation problem since investment decisions are control variables that affect the value of the asset. We can then calculate the effects of tax policy changes on both the value of the project and the investment decision.

One might be tempted to simply assert that a project's value $V(\cdot)$ is equal to the expected discounted value of cash flows. However, if the firm's shareholders are risk averse their required return - and hence, the appropriate discount rate - will depend on the risk characteristics of the cash flows. Thus we need a procedure for determining the correct rate of discount. In fact, if the cash flows depend on the firm's operating decisions, the discount rate depends on both the risk characteristics of the state variables and the control decisions, i.e. it is endogenous.

The approach I take is to use a model of capital market equilibrium to determine what the value of the asset must be in a competitive economy. The equilibrium model of asset markets determines the required expected rate of return on the project in equilibrium. To solve for the project value, one sets the equilibrium return equal to the actual return on the project and integrates. The method solves the problem of determining the correct discount rate for the cash flows. I shall now formalize the details of the approach.

\subsection{Valuing risky assets}

Consider an asset whose value depends on an $(n \times 1)$ vector of state variables, $x$, and a control policy functional, $\psi \in \Psi$, with $\Psi$ a compact space. ${ }^{5}$ Assume that the state variables are generated by a joint Itô diffusion process:

$$
\mathrm{d} \boldsymbol{x}=\alpha(\boldsymbol{x}, \psi) \mathrm{d} t+\Sigma^{1 / 2}(\boldsymbol{x}, \psi) \mathrm{d} \boldsymbol{z}
$$

where $\alpha$ is an $(n \times 1)$ vector-valued function, and $\Sigma^{1 / 2}$ an $(n \times n)$ matrix-valued function. ${ }^{6}$ The instantaneous expectation and covariance of the $x_{i}$ are given

\footnotetext{
${ }^{4}$ Brennan and Schwartz (1986) allow for the possibility of taxes in their andysis, but do not study any policy effects.

${ }^{5}$ The asset may be, for example, a new factory, or a lease right to develop a mine.

${ }^{6} \Sigma^{1 / 2}$ is the symmetric Cholesky matrix for the positive semi-definite variance-covariance matrix $\Sigma$ which has representative element $\sigma_{i j}$.
} 
by $\mathrm{E}\left(\mathrm{d} x_{i}\right)=\alpha_{i}(x, \psi)$ and $\operatorname{Cov}\left(\mathrm{d} x_{i}, \mathrm{~d} x_{j}\right)=\sigma_{i j}(x, \psi)$, respectively. The $\mathrm{d} z_{i}$ are Gaussian increments.

The Itô process formulation states that a state variable (such as output price) has a deterministic growth trend $\alpha \mathrm{d} t$ and an unpredictable random component $\sigma \mathrm{d} z$ (possibly with other stochastic terms entering through the covariances). In general, both the drift and shock may depend on the state of the system, $\boldsymbol{x}$, and the control choices made by the agent, $\psi^{7}$ In the simplest case $\alpha$ and $\sigma^{2}$ are constants and $x_{i}$ follows a random walk with drift $\alpha$.

As described above, we can use capital market conditions to determine what the value of the asset must be in equilibrium. If we assume perfect markets, homogeneous expectations and time-additive von NeumannMorgenstern investor preferences, then it is possible to generalize Merton's (1973b) intertemporal capital asset pricing model to obtain a model with taxes on elements of corporate cash flows. ${ }^{8}$ In equilibrium, security returns must satisfy the relationship:

$$
\xi_{i}-r=\lambda \rho_{i M} \sigma_{i}
$$

where $\xi_{i}$ is the instantaneous expected after-tax rate of return on security $i$ (as determined by the equilibrium), $r$ is the risk-free interest rate, $\rho_{i M}$ is the instantaneous correlation coefficient between the market portfolio and security $i$, and $\lambda \equiv\left(\xi_{m}-r\right) / \sigma_{M}$, with $\xi_{M}$ and $\sigma_{M}^{2}$ the expected return and variance of the market portfolio. ${ }^{9}$ The result simply states that the fundamental principle of no excess returns in competitive equilibrium must hold in an intertemporal setting as well as in a static model: in equilibrium an asset must earn a return equal to the risk-free rate plus a premium for nondiversifiable risk.

The stochastic equilibrium approach to project valuation was first proposed by Constantinides (1978). Following that paper, the instantaneous certainty-equivalent return on the asset is equal to the cash flow plus riskadjusted expected capital gain; arbitrage requires that this return be equal to the opportunity cost of holding the asset, $r V$. Define $\Pi^{\mathrm{AT}}(\boldsymbol{x}, t ; \psi)$ as the after-tax cash flow given control policy $\psi$. Let the value of the asset to the firm at time $t$ be $V(x, t, \psi)$, which indicates that the value may depend on the

\footnotetext{
${ }^{7}$ The major restriction imposed by the diffusion assumption is that the time path of the state variables, while almost nowhere differentiable, is almost everywhere continuous. Thus, it does not allow for measurable jumps such as a Poisson process might generate. The analytics are much less tractable when a Poisson process is incorporated, although some results have been obtained for simple problems. See Merton (1981) for a detailed discussion of the stochastic process assumption.

${ }^{8}$ I discuss alternative approaches that rely on different assumptions below.

${ }^{9} I$ assume the market parameters are constants; Merton also derives a result for a nonconstant opportunity set.
} 
state variables, time and the control decisions, $\psi$, taken by the firm. Apply Itô's Lemma to $V(\cdot)$ to get the expected instantaneous rate of capital gain on the project: $(1 / \mathrm{d} t) \mathrm{E}_{t} \mathrm{~d} V=V_{\mathrm{t}}+\sum_{i} \alpha_{i} V_{i}+\frac{1}{2} \sum_{i} \sum_{j} \sigma_{i j} V_{i j}$ (subscripts on $V$ denote differentiation). ${ }^{10}$ As Constantinides shows, we can substitute the expected return and variance into the market equilibrium condition (1) to obtain the certainty equivalent of the expected earnings rates, $\alpha_{i}: \tilde{\alpha}_{i}=\alpha_{i}-\lambda \rho_{i M} \sigma_{i}$. Setting the certainty-equivalent gain plus cash flow equal to $r V$ yields an equation that can be solved for the project value, $V$ :

$$
\max _{\psi \in \Psi}\left\{\frac{1}{\mathrm{~d} t} \mathrm{E}_{t}^{*} \mathrm{~d} V+\Pi^{\mathrm{AT}}\right\}=r V
$$

where $\mathrm{E}_{t}^{*}$ indicates the expectation with respect to the risk-adjusted distribution, with $\tilde{\alpha}_{i}$ replacing $\alpha_{i}$. This is the stochastic Bellman equation for the problem; explicitly written, $V(x, t, \psi)$ must solve

$$
\max _{\psi \in \Psi}\left\{\Pi^{\mathrm{AT}}+V_{t}+\sum_{i=1}^{n}\left(\alpha_{i}-\lambda \rho_{i M} \sigma_{i}\right) V_{i}+\frac{1}{2} \sum_{i=1}^{n} \sum_{j=1}^{n} \sigma_{i j} V_{i j}-r V\right\}=0
$$

subject to boundary conditions appropriate to the asset.

If there is a unique maximizing control policy, $\psi^{*}$, the asset value can be determined from (2) and the boundary conditions. When there is only one state variable the partial differential equation is parabolic and is easily solved by numerical methods. ${ }^{11}$ With more state variables the problem is elliptical; numerical solution is more difficult but is often feasible, sometimes by using Monte Carlo methods. ${ }^{12}$ For some problems the solution can be obtained analytically, as in section 4 of this paper.

What is special about eq. (2)? It appears to be a standard Bellman equation. The important point is that shareholders are not assumed to be risk neutral. Instead, by assuming enough to obtain a tractable intertemporal capital market model, we can handle the endogenous rate of discount.

The usefulness of this approach is emphasized by another interpretation of eq. (2). Note that risk preferences do not appear, thus the equation must hold for any preferences, including risk neutral. In a risk-neutral world we can derive the Bellman equation directly, and it would be precisely (2) if the price drift happened to be $\tilde{\alpha}_{i} \equiv \alpha_{i}-\lambda \rho_{i M} \sigma_{i}$ instead of $\alpha$. Thus, eq. (2) tells us that we can value the asset as if the firm were risk neutral if we replace the

\footnotetext{
${ }^{10}$ See Merton (1981) for an introduction to the stochastic calculus. The capital gain involves second-order terms in $V_{i j}$ due to the characteristics of an Itô process.

${ }^{11}$ See Geske and Shastri (1985) and Brennan and Schwartz (1978).

${ }^{12}$ Lund (1987) and Majd and Myers (1985, 1986) solve valuation problems using Monte Carlo.
} 
drift $\alpha_{i}$ with $\tilde{\alpha}_{i}$ in the state variable distributions. We thus can value the asset by its expected discounted cash flows, as long as we adjust the distributions appropriately. ${ }^{13}$ The method can be viewed as the 'correct' way to calculate a risk-adjusted discounted present value, in which each stochastic component gets its own risk-adjusted discount rate (adjusted for its own risk characteristics), $r+\hat{\lambda} \rho_{i M} \sigma_{i}$.

The capital market assumptions used to derive (2) are restrictive. The valuation approach may still be useful under less restrictive circumstances, however. For example, suppose that traded securities exist whose returns are perfectly correlated with the state variables, $\boldsymbol{x}$ (i.e. they span the state space). ${ }^{14}$ Then, a simple arbitrage argument yields precisely eq. (2) except that $\alpha_{i}-\lambda \rho_{i M} \sigma_{i}$ is replaced by some $\tilde{\alpha}_{i}^{*}$ determined by the stochastic parameters of the spanning securities. Even without either spanning or a simple equilibrium model the Bellman equation holds quite generally, conditional on the unknown appropriate risk-adjusted discount rates. An analysis could proceed with qualitatively similar results by positing the riskadjustment factors appropriate for the asset. ${ }^{15}$ Thus, the valuation method embodied in eq. (2) is quite robust.

\subsection{Investment decisions}

In this section I shall show how to use the stochastic equilibrium valuation method to analyze optimal investment decisions with nonlinear taxation. I treat this special case of valuing the general control problem because we are often particularly interested in the effects of taxes on investment decisions.

I first discuss the intuition behind investment decisions in a stochastic and dynamic problem. If a firm has an opportunity to invest in a project it will be optimal to invest if the risk-adjusted expected return on the project exceeds the opportunity cost. If the opportunity is available now but tomorrow disappears foreover, then the decision follows the familiar static rule: invest if the expected risk-adjusted net present value is positive. However, if the firm retains the opportunity to invest, then the decision rule must take into account the return to holding on to the opportunity without investing today. That is, there may be a value from waiting; this value has been studied in McDonald and Siegel (1986).

Waiting has no value if proceeding with the investment does not change the firm's opportunity set. If opportunitics are unchanged, then the firm should go ahead with any project which has a positive risk-adjusted present value. Should the return from starting tomorrow turn out to be higher than

\footnotetext{
${ }^{13}$ This result was first noted for valuing financial options by Cox and Ross (1976).

${ }^{14} \mathrm{As}$ an example, if the state variable is output price then a traded futures contract on the output should be perfectly correlated under standard assumptions.

${ }^{15}$ Pindyck (1988) discusses this justification for using the Bellman equation.
} 
from starting today, the firm can commence another, identical project tomorrow.

Suppose instead that an opportunity, once exercised, cannot be exactly duplicated. Mining projects have this characteristic since reserves are finite and ore once extracted cannot be extracted again. Investing and producing now kills the option to produce that same ore at a higher price later. Thus the risk-adjusted value of the ore may be greater if left in the ground than extracted. Killing the option to extract later is part of the opportunity cost of immediate investment. ${ }^{16}$

To analyze investment decisions we can value the opportunity to invest in an irreversible project and determine when it is optimal to exploit that opportunity. Consider a firm which owns the perpetual right to invest in a project that has a sunk cost $I$. Call the value of this (lease) right $L(p, I, t)$, with $p$ the stochastic output price of the project. Let the dynamics of price be $\mathrm{d} p=\alpha p \mathrm{~d} t+\sigma p \mathrm{~d} z$. The asset has value $V(p, t, \psi)$ if investment occurs, as determined by eq. (2).

For this problem it is easy to derive the optimal investment decision. Since the price is assumed to follow a stationary geometric random walk with known drift, the optimal control policy is stationary and Markovian. There must be a critical initial price, $p^{I}$ (independent of calendar time), above which it invests immediately, and below which it waits for higher prices. If the firm invests it pays $I$ and gets an asset worth $V(\cdot)$ so market equilibrium requires that at the critical price the lease value be

$$
L\left(p^{I}, t, \psi^{*}\right)=V\left(p^{I}, t, \psi^{*}\right)-I^{\mathrm{AT}},
$$

where $\psi^{*}$ indicates that all other control functionals are chosen optimally, and $I^{\mathrm{AT}}$ is the after-tax investment cost. Since the firm is free to choose optimally the critical price, the following marginal ('high-contact') condition is necessary [Merton (1973b)]:

$$
L_{p}\left(p^{I}, t, \psi^{*}\right)=V_{p}\left(p^{I}, t, \psi^{*}\right)
$$

The fundamental valuation of eq. (2) for this problem is a parabolic partial differential equation:

$$
\frac{1}{2} \sigma^{2} p^{2} L_{p p}+\tilde{\alpha} p L_{p}+L_{t}-r L=0,
$$

with $\tilde{\alpha}=\alpha-\lambda \rho \sigma$. The solution of (5) with boundary conditions (3) and (4)

\footnotetext{
${ }^{16}$ Pindyck (1988) takes a similar approach to model irreversible investment in capacity as killing an option to invest later. MacKie-Mason (1987) studies a dynamic investment problem in which the firm faces a sequence of options to change its investment plan after learning new information.
} 
yields the equilibrium value of the investment opportunity, $L$, and the critical price, $p^{I}$, which represents the optimal investment decision.

\section{Effects of a percentage depletion allowance}

I now analyze the effects of the nonlinear U.S. percentage depletion allowance (PDA) on the asset value and investment decisions of mining firms. Previous analyses treat the allowance as a simple linear subsidy. Actual depletion allowances usually have limits that introduce kinks in the subsidy function, and sometimes other nonlinearities. This section presents an explicit solution with analytical comparative statics. In section 4 I numerically analyze a more general investment problem in which the firm is able repeatedly to open and close the mine.

U.S. mining firms are allowed to deduct a percentage of gross revenues from taxable income as an allowance for the decrease in the economic value of the resource as it is mined. ${ }^{17}$ While acknowledging that the PDA is a subsidy, proponents have argued that it is a desirable mechanism for providing incentives for investment in such risky enterprises. ${ }^{18}$

The most important results derived below are that the subsidy may actually discourage investment in some projects, shutdown of marginal projects may be encouraged, and effective marginal tax rates will vary with the riskiness of a project. The interaction between the nonlinear PDA and uncertainty also leads to the result that increasing the corporate income tax rate may encourage some investments.

\subsection{Tax rules and project value}

Consider a firm valuing an incremental mining project. The firm owns the right to extract a known quantity of reserves, $R$. I assume for now that the mine produces at a fixed rate of $\bar{q}$ for $T \equiv R / \bar{q}$ years. Unit extraction cost is known and constant, at $c .^{19}$ The firm plans to sell its output on the spot market.

The output price is uncertain, with the amount of uncertainty increasing

\footnotetext{
${ }^{17}$ Percentage depletion has not been allowed for the 'major' oil and gas producers since 1975. The PDA is still available to 'miners' and to all producers in most hard-rock mining industries.

${ }^{18} \mathrm{Sec}$, for example, Glen (1985) and Clark (1985) for statements by oil and gas industry lobbyists.

${ }^{19}$ The restriction on output control allows me to obtain analytical results and an intuitive understanding of the interaction between the nonlinear tax policy and uncertainty. I consider a more flexible output decision in section 4. I introduced both cost and geological uncertainty in MacKie-Mason (1986). Explicit comparative statics are still possible with both price and cost uncertainty. Some of the more general results are interesting, but the qualitative implications are unchanged.
} 
with the length of the forecast horizon. The stochastic dynamics of the exogenous price are:

$$
\mathrm{d} p=\alpha p \mathrm{~d} t+\sigma p \mathrm{~d} z
$$

The increasing forecast uncertainty is given by the variance of $p(s)$ viewed at time $t: \sigma^{2} p^{2}(s-t) .^{20}$

The annual after-tax cash flows from the mine will be $(p-c) \bar{q}-T A X(p, \bar{q})$. I consider two different rules for corporate income taxation. The first gives full loss refunds, i.e. if the firm has a taxable loss in a period the government refunds the negative tax liability. The second rule allows no loss refunds. Actual U.S. rules fall somewhere in between, with provisions for limited and undiscounted loss carrybacks and carryforwards. I focus on the bracketing cases to isolate the effects of the asymmetry in the PDA.

I assume that capital expenditures are expensed which focuses attention on the PDA without affecting the qualitative results. ${ }^{21}$ Setting the depletion allowance rate to zero for a moment, tax liabilities under the full-refunds and no-refunds rule are:

$$
T A X^{\mathrm{F}}=\tau(p-c) \bar{q}, \quad T A X^{\mathrm{N}}=\tau \max [p-c, 0] \bar{q}
$$

where superscripts $\mathrm{F}$ and $\mathrm{N}$ are used to denote 'full refunds' and 'no refunds', respectively.

With a PDA firms may deduct $100 \delta$ percent of gross income from taxable income, not to exceed 50 percent of net income. Since the PDA is a voluntary deduction the firm does not subtract 50 percent of a negative amount if net income is negative. Tax liability under the full-refunds rule is:

$$
T A X^{\mathbf{F}}(p, \bar{q})= \begin{cases}\tau(p-c) \bar{q}-\tau \min [\delta p \bar{q}, 0.5(p-c) \bar{q}], & \text { if } p \geqq c, \\ \tau(p-c) \bar{q}, & \text { otherwise }\end{cases}
$$

or

$$
T A X^{\mathrm{F}}(p, \bar{q})=\min \{\tau(p-c) \bar{q}, 0.5 \tau(p-c) \bar{q}+0.5 \tau \bar{q} \max [\beta p-c, 0]\}
$$

$(T A X F)$,

where $\beta=(0.5-\delta) / 0.5$. Tax liabilities with no loss refunds are:

\footnotetext{
${ }^{20} \mathrm{I}$ am ignoring the general equilibrium effects of a PDA by assuming prices are exogenous and unaffected by tax policy changes. Note, however, that eq, (6) is consistent with the Hotelling rule for exhaustible resource industry equilibrium: setting $\alpha=r$ (the rate of interest) and $\sigma=0$ yields $\dot{p} / p=r$. I study some general equilibrium effects of the PDA in MacKie-Mason (1984).

${ }^{21}$ Many countries allow substantial expensing of mining capital investments as 'intangible' expenditures.
} 


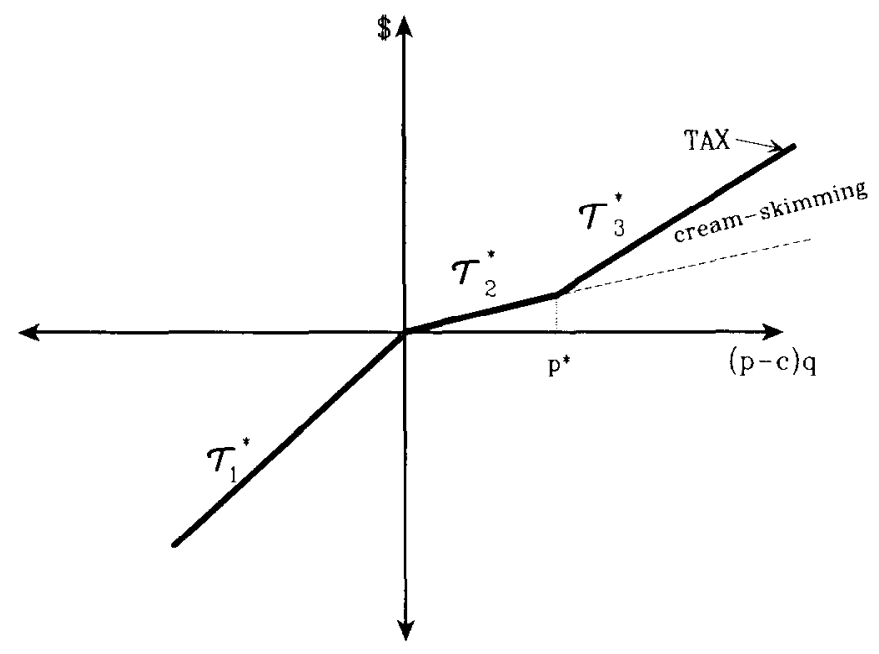

Fig. 1. Tax liabilities with full loss offsets. $\tau_{1}^{*}$ is the marginal tax rate on losses; $\tau_{2}^{*}$ is the marginal tax rate with the percentage depletion allowance below the cap; and $\tau_{3}^{*}$ is the marginal tax rate above the cap (the 'cream-skimming' region).

$$
T A X^{\mathrm{N}}(p, \bar{q})=\tau \bar{q}\{\max [p-c, 0]-0.5(\max [p-c, 0]-\max [\beta p-c, 0])\}
$$

$(T A X \mathrm{~N})$.

Tax liabilities under the different rules are illustrated in figs. 1 and $2 .{ }^{22}$ In fig. 1 the firm receives full loss refunds. Without a PDA the government takes a constant fraction $\tau$ of net income. Now consider tax revenue with a PDA from left to right in the figure. When net income is negative, the government still refunds the fraction $\tau$; call the tax rate in this region $\tau_{1}^{*}$. If net income is positive, the government using a PDA takes a lower base fraction, $\tau_{2}^{*}=0.5 \tau$. When the firm is fortunate - i.e. when price is high enough for $p>p^{*}$ - the government takes an additional bite through the contingent claim (the max $\left[{ }^{\circ},\right]$ term in $(T A X F)$ ). I refer to this additional tax bite under the PDA as 'cream-skimming'. The cream-skimming region begins at $p^{*}=[0.5 /(0.5-\delta)] \times c$; that is, when $p$ is sufficiently high that $100 \delta$ percent of gross revenue is less than 50 percent of net income. The marginal tax rate in the cream-skimming region is $\tau_{3}^{*}=(1-\delta) \tau^{23}$

This valuation problem exhibits the difficulties discussed in section 2 . With the PDA there are three possible marginal tax rates, so expected after-tax cash flow will be a nonlinear function of the random price. With risk-averse

\footnotetext{
${ }^{22}$ The horizontal axis is measured in pre-tax net income, but unit costs, $c$, and output, $\bar{q}$, are held constant, so only $p$ is increasing.

${ }^{23}$ The depletion rate $\delta$ must be less than 0.5 .
} 


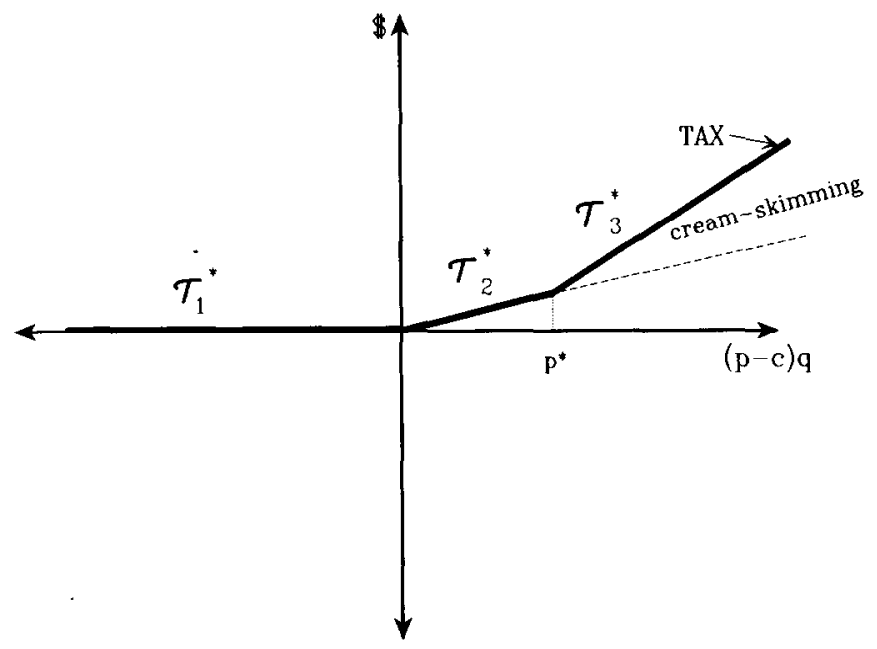

Fig. 2. Tax liabilities with no loss offsets. $\tau_{1}^{*}$ is the marginal tax rate on losses; $\tau_{2}^{*}$ is the marginal tax rate with the percentage depletion allowance below the cap; and $\tau_{3}^{*}$ is the marginal tax rate above the cap (the 'cream-skimming' region).

investors the appropriate discount rate depends on the price of risk. However, with the stochastic equilibrium valuation method the problem is straightforward and tractable.

To find the value of the project recall that we can modify the distribution of prices by replacing $\alpha$ with $\tilde{\alpha} \equiv \alpha-\lambda \rho \sigma$ [where $\rho$ is the instantaneous correlation coefficient between the output price and the market of traded assets and $\lambda$ is the 'market price of risk' defined in eq. (1)], and then evaluate the expected value of the firm's (modified) cash flows discounted at the riskfree rate. That is, letting $\Pi^{\mathrm{AT}}$ denote the after-tax cash flows and $\mathrm{E}_{0}^{*}$ indicate mathematical expectation as of time zero with respect to the modified price distribution, the value of the mine is:

$$
V\left(p_{0}, 0\right)=\mathrm{E}_{0}^{*} \int_{0}^{T} \Pi^{\mathrm{AT}}(p, t) \mathrm{e}^{-r t} \mathrm{~d} t
$$

Capital market equilibrium determines the correct discount rate through the modification of the price distribution.

We now can evaluate directly the expected value of the government's nonlinear contingent tax claims on the project's cash flows. Let

$$
W\left(p_{0}, t, c\right)=\mathrm{E}_{0}^{*} \mathrm{e}^{-r t} \max [p(t)-c, 0] .
$$


$W\left(p_{0}, t, c\right)$ is the market value at time zero of a claim on the greater of $p(t)-c$ and zero. Since $c$ is known and nonstochastic, $W(\cdot)$ is the value of an option to pay $c$ at time $t$ for an asset whose price is $p(t)$, If $p-c>0$ at $t$ the owner of the option exercises it, paying $c$ and getting an asset worth $p$. If $p-c<0$ at $t$ the option is 'out of the money' or worthless and the owner does nothing. This is a European call option on an asset with a belownormal rate of return (assuming $\tilde{\alpha}<r$ ). ${ }^{24}$ In the full-refunds case the firm 'owns' a call option on $0.5 \tau$ of net income if $p>c$, and the government owns a similar call on $0.5 \tau$ of $\beta p-c$ if $\beta p>c$.

To calculate $W\left(p_{0}, t, c\right)$ note that $p$ is distributed lognormally and integrate to evaluate the expectations: ${ }^{25}$

$$
\begin{aligned}
& W\left(p_{0}, t, c\right)=\mathrm{e}^{-\mu t} p_{0} \Phi\left(d_{1}\right)-\mathrm{e}^{-r t} c \Phi\left(d_{2}\right), \\
& \mu=r-\tilde{\alpha}, \\
& d_{1}=\frac{\ln \left[p_{0} / c\right]+\left[r-\mu+\sigma^{2} / 2\right] t}{\sigma \sqrt{t}}, \\
& d_{2}=d_{1} \quad \sigma \sqrt{t},
\end{aligned}
$$

where $\Phi(\cdot)$ is the standard normal cumulative distribution (I later use $\phi$ to denote the density).

Now we can find the value of the mine under the two tax regimes. Consider the no-loss-refunds case, with cash flow $(p-c) \bar{q}-T A X^{\mathrm{N}}(p, \bar{q})$. From eq. (7) we have:

$$
V^{\mathrm{N}}\left(p_{0}, 0\right)=\mathrm{E}_{0}^{*} \int_{0}^{T}\left[(p-c) \bar{q}-T A X^{\mathrm{N}}(p, \bar{q})\right] \mathrm{e}^{-r t} \mathrm{~d} t .
$$

Substituting expression (TAXN) yields:

$$
V^{\mathrm{N}}\left(p_{0}, 0\right)=\bar{q} \mathrm{E}_{0}^{*} \int_{0}^{T}[(p-c)-0.5 \tau\{\max [p-c, 0]+\max [\beta p-c, 0]\}] \mathrm{e}^{-r t} \mathrm{~d} t,
$$

\footnotetext{
${ }^{24}$ The normal risk-adjusted return is $r$. If the inequality is reversed the firm would never extract the resources because the risk-adjusted expected return would be greater in situ. I am thus allowing for the resource to have a 'convenience yield', or some additional return to having the resource already extracted and in hand rather than having a claim on it in the future. Call options of this sort have been studied in McDonald and Siegel (1984).

${ }^{25} \mathrm{Eq}$. (22) in Smith (1976) provides a convenient exposition of the integral result; the same integral is also evaluated at eq. (10) in Constantinides (1978).
} 
and evaluating with the result for $W\left(p_{0}, t, c\right)$ yields:

$$
\begin{aligned}
V^{\mathrm{N}}\left(p_{0}, t\right)= & \bar{q} \int_{0}^{T}\left\{\left(p_{0} \mathrm{e}^{\tilde{\alpha} t}-c\right)-0.5 \tau\left[\left(p_{0} \mathrm{e}^{\tilde{\alpha} t} \Phi\left(d_{1}\right)-c \Phi\left(d_{2}\right)\right)\right.\right. \\
& \left.\left.+\left(\beta p_{0} \mathrm{e}^{\tilde{\alpha} t} \Phi\left(\hat{d}_{1}\right)-c \Phi\left(\hat{d}_{2}\right)\right)\right]\right\} \mathrm{e}^{-r t} \mathrm{~d} t
\end{aligned}
$$

where $\beta \equiv(0.5-\delta) / 0.5$, and $\hat{d}_{i}$ is equal to $d_{i}\left(p_{0}\right)$ defined in (8) but evaluated at $\beta p_{0}$. Proceeding likewise for the full-refunds case yields:

$$
\begin{aligned}
V^{\mathbf{F}}\left(p_{0}, t\right)= & \bar{q} \int_{0}^{T}\left\{(1-\tau)\left(p_{0} \mathrm{e}^{\tilde{\alpha} t}-c\right)\right. \\
& +0.5 \tau\left[\left(p_{0} \mathrm{e}^{\tilde{\alpha} t} \Phi\left(d_{1}\right)-c \Phi\left(d_{2}\right)\right)\right. \\
& \left.\left.-\left(\beta p_{0} \mathrm{e}^{\tilde{\alpha} t} \Phi\left(\hat{d}_{1}\right)-c \Phi\left(\hat{d}_{2}\right)\right)\right]\right\} \mathrm{e}^{-r t} \mathrm{~d} t .
\end{aligned}
$$

The several components of tax liability identified earlier can be seen in the pieces of the integrands.

Before examining in detail the effects of tax policy, let us briefly consider the effects of some of the other parameters on the asset value. $W\left(p_{0}, t, c\right)$ is an option on an 'underpriced' asset and its comparative statics have been derived elsewhere [e.g. McDonald and Siegel (1984) and MacKie-Mason (1986)]:

$$
\begin{aligned}
& \frac{\partial W}{\partial p_{0}}=\mathrm{e}^{-\mu t} \Phi\left(d_{1}\right) \\
& \frac{\partial W}{\partial \sigma^{2}}=-t \frac{\partial \mu}{\partial \sigma^{2}} \mathrm{e}^{-\mu t} p_{0} \Phi\left(d_{1}\right)+\mathrm{e}^{-r t} c \phi\left(d_{2}\right) \frac{\sqrt{t}}{2 \sigma} \\
& \frac{\partial W}{\partial c}=-\mathrm{e}^{-r t} \Phi\left(d_{2}\right) .
\end{aligned}
$$

These results (and similar calculations for $\partial W / \partial t$ and $\partial W / \partial r$ ) can be used to investigate the sensitivity of the results to the parameters in a particular case. For example, the dependence of the asset value on the initial price in the norefunds case is given by:

$$
\frac{\partial V^{\mathbf{N}}}{\partial p_{0}}=\bar{q} \int_{0}^{T}\left\{1-0.5 \tau\left[\Phi\left(d_{1}\right)-\beta \Phi\left(\hat{d}_{1}\right)\right]\right\} \mathrm{e}^{-\mu t} \mathrm{~d} t .
$$


Since $d_{1}>\hat{d}_{1}, \beta<1$, and $\Phi(\cdot)$ is increasing and bounded above by unity, $\sup \left[\Phi\left(d_{1}\right)-\beta \Phi\left(\hat{d}_{1}\right)\right]=1$ over admissible parameter space, and $\partial V^{\mathrm{N}} / \partial p_{0}>0$. Similarly, second-order comparative statics can be obtained on all of the tax policy effects below; some of the results are indicated in the numerical analysis in section 4 .

\subsection{Effect of tax policy changes on asset value}

I now derive the comparative statics of asset value with respect to the corporate tax rate and the PDA rate. The most important result in this section is to show that typical calculations overstate the amount of the PDA subsidy to the firm by ignoring the interaction between uncertainty and nonlinearity.

First consider the corporate tax rate:

Result 1. With full loss refunds, an increasc in the corporate income tax rate will lower (raise) the value of the mine if expected pre-tax profits are positive (negative). With no loss refunds the corporate tax always reduces mine value. ${ }^{26}$

To show the result for the full-refunds case, differentiate (10) with respect to $\tau$ and rearrange:

$$
\frac{\mathrm{d} V^{\mathrm{F}}}{\mathrm{d} \tau}=\int_{0}^{T}\left\{-\left(p_{0} \mathrm{e}^{-\mu t}-c \mathrm{e}^{-r t}\right) \bar{q}+0.5 \bar{q}\left[W\left(p_{0}, t, c\right)-W\left(\beta p_{0}, t, c\right)\right]\right\} \mathrm{d} t .
$$

The integrand is negative if and only if expected period profits, $\left(p_{0} \mathrm{e}^{-\mu t}-c \mathrm{e}^{-r t}\right) \bar{q}$ are positive. This is true because $W\left(p_{0}, t, c\right)$ is bounded above by expected period profits and $W\left(\hat{p}_{0}, t, c\right)$ is bounded below by zero, so the difference between them can never be twice as great as expected profits. The difference is always positive because a call option is increasing in the value of its price argument. ${ }^{27}$

The intuition for the result is straightforward. For a firm with positive income on average, a higher corporate tax rate increases both ordinary tax payments [the first term in (11)] and the PDA subsidy (the second term). However, since the PDA subsidy is limited to no more than 50 percent of the ordinary tax liability, the first effect dominates and the asset value falls. For a loss firm a tax rate increase is a benefit when the tax loss liabilities are refunded because refunds increase and the PDA is irrelevant for losses. When

\footnotetext{
${ }^{26}$ 'Expected' profits are calculated with respect to the modified price distribution.

${ }^{27}$ See, for example, Merton (1973b). The higher is the initial price, the more likely that the call will pay off.
} 
there are no loss refunds, the increased tax rate affects only the positive income years for any firm, and thus all asset values decrease.

Now consider the PDA subsidy rate:

Result 2. The value of a mine is strictly increasing in the percentage depletion allowance rate.

The derivative under both refund rules is:

$$
\frac{\mathrm{d} V}{\mathrm{~d} \delta}=-\int_{0}^{T} \frac{\partial W\left(\beta p_{0}, t, c\right)}{\partial \delta} \mathrm{d} t
$$

Since $\beta p=[(0.5-\delta) / 0.5] p$, the sign on $\partial W / \partial p$ is opposite to the sign of $\partial W / \partial \delta$. A call is increasing in the price term, yielding the result.

Result 2 can be understood with fig. 1. Increasing the PDA rate raises the critical value $p^{*}$, and lowers the slope of the cream-skimming region. Thus, tax liabilities are (weakly) lower in all states of the world and strictly lower for high prices. Put another way, the government's cream-skimming makes the tax function less convex and reducing the convexity of a function lowers its expected value.

Calculations that ignore the interaction between uncertainty and nonlinearity will overstate the value of the PDA to firms. The estimates of the subsidy prepared by the U.S. Treasury forecast an expected price path, then calculate the subsidy value based on expected prices. This calculation violates Jensen's Inequality: since the PDA convexifies the government's tax claim on stochastic revenues, we know that

$$
\mathrm{E}[T A X(p)]>T A X(\mathrm{E}[p])
$$

The government gets the cream-skimming claim when a mine pays off well, but does not give anything extra back to the firm when revenues are low. Thus, the economic value of the subsidy is less than the usual calculations indicate.

\subsection{The effect of risk on the PDA subsidy}

The PDA has been justified as compensation for the riskiness of mining. To the contrary, I show here that the subsidy value decreases as risk increases. Thus, the PDA causes marginal effective tax rates to vary with project riskiness. The following result holds whether losses are refunded or not:

Result 3. If project value is nonincreasing in risk without the PDA, then for 
a large enough initial margin $\left(p_{0}-c\right)$ riskier projects receive smaller subsidies.

I discuss the meaning of 'large enough' below. ${ }^{28}$ To see the result for the full-refunds case, differentiatc (10) with respect to the instantaneous price variance: ${ }^{29}$

$$
\frac{\partial V^{\mathrm{F}}}{\partial \sigma^{2}}=\gamma \frac{\partial V^{\mathrm{F} 0}}{\partial \sigma^{2}}+0.5 \tau \bar{q} c \int_{0}^{T} \mathrm{e}^{-r \tau} \frac{\sqrt{ } t}{2 \sigma}\left[\phi\left(d_{2}\right)-\phi\left(\hat{d}_{2}\right)\right] \mathrm{d} t
$$

where

$$
\begin{aligned}
& \gamma=\frac{1-\tau+0.5 \tau \Gamma(T)}{1-\tau}, \\
& \Gamma(T)=\frac{\int_{0}^{T} t \mathrm{e}^{-\mu t}\left(\partial \mu / \partial \sigma^{2}\right)\left[\Phi\left(d_{1}\right)-\beta \Phi\left(\hat{d}_{1}\right)\right] \mathrm{d} t}{\int_{0}^{T} t \mathrm{e}^{-\mu t}\left(\partial \mu / \partial \sigma^{2}\right) \mathrm{d} t},
\end{aligned}
$$

and $V^{\mathrm{FO}}$ indicates the value of the mine without a PDA.

As noted earlier, $d_{1}>\hat{d}_{1}, \beta<1$ and $\Phi(\cdot)$ is bounded above by unity, so we have $0<\Gamma(T)<1 .^{30}$ Thus, $\gamma>1$ and the first term of (12) is a multiplier on the aversion to risk without a PDA. Since $\phi(\cdot)$ is the Gaussian density the second expression in (12) is also negative when $p_{0}-c$ is sufficiently large, and therefore the decline in value of the mine is greater with a PDA than without.

The intuition can be seen with fig. 1. The firm pays the ordinary income tax, but receives back the difference between two contingent claims [see eq. (10)]. The convexity of these claims causes their value (to the firm and the government, respectively) to increase in risk. If the initial margin $\left(p_{0}-c\right)$ is low, then higher risk increases the probability of obtaining the PDA subsidy at all (the firm's claim), since there is no subsidy if net income is negative. Thus, the increase in the value of the firm's contingent claim on the government can dominate the increase in cream-skimming value, with the net PDA subsidy increasing in risk. That is, the integral expression in (12) may

\footnotetext{
${ }^{28}$ The premise of the result limits consideration to the natural case in which price risk does not increase asset value before taxes. Project value could increase in risk if, for instance, the output price covaried negatively with the market; the risk premium $\lambda \rho \sigma$ would then be negative.

${ }^{29}$ Merton (1973b) shows that when the stochastic process is Ito, increasing variance is equivalent to increasing risk in the Rothschild and Stiglitz (1970) sense. .

${ }^{30} \mathrm{I}$ assume that investment opportunities are constant through time, so that $\tilde{\alpha}$ and $r$ (hence $\mu$ ) are constants over time. If the signs on $\partial \mu / \partial \sigma^{2}$ could change over time, then $\Gamma<0$ is possible. However, the requirement that $\partial V^{\mathrm{FO}} / \partial \sigma^{2}<0$ imposes restrictions on $\partial \mu / \partial \sigma^{2}$ that make this implausible. I am grateful to Diderik Lund for raising this concern.
} 
dominate the multiplier $\gamma$ so that the PDA reduces the loss in mine value from increased risk.

If the margin is high enough, then an increase in risk primarily increases the probability of government cream-skimming. Then the PDA subsidy decreases with price risk because the multiplier $\gamma$ is greater than unity and the second term is small or negative.

How large does the margin have to be for the PDA subsidy to decrease with risk? The expression $\phi\left(d_{2}\right)-\phi\left(\hat{d}_{2}\right)$ must be small or negative. That is, the marginal effect on the probability of the government exercising its contingent claim (cream-skimming) must be greater than the effect on the probability of the firm exercising its claim (the subsidy for positive $p$ ). Since $d_{2}>\hat{d}_{2}$ the necessary condition (for a given year $t$ ) will be satisfied for any $\hat{d}_{2}$ greater than a critical value $\hat{d}_{2}^{*}$. This critical value falls below zero since $\phi(\cdot)$ is symmetric around zero. Thus, the subsidy can decrease even if the current price is below cost, since $d_{2}$ can be negative for $p_{0}-c<0$ if $\tilde{\alpha}-\sigma^{2} / 2$ is large enough. Furthermore, the larger is $\gamma$ the weaker is the restriction on $p_{0}-c$. In the numerical calculations reported in section 4 the subsidy value decreases in risk whenever price is high enough for the mine to be open.

\subsection{Effects on investment decisions}

I now investigate the effects of the corporate tax rate and the PDA on investment decisions. The results are surprising: increasing the corporate tax rate can encourage investment, while increasing the PDA rate can discourage investment. These results emphasize the importance of taking tax nonlinearities into account.

I examine the investment decision by evaluating the value of a lease right to develop a project conditional on the optimal exercise of the investment option. In section 2 I showed that the lease value must satisfy a stochastic equilibrium Bellman equation and two boundary conditions, restated here for convenience: ${ }^{31}$

$$
\begin{aligned}
& \frac{1}{2} \sigma^{2} p^{2} L_{p p}+\tilde{\alpha} p L_{p}-r L=0, \\
& L\left(p^{I}, t, \psi^{*}\right)=V\left(p^{I}, t, \psi^{*}\right)-(1-\tau) I, \\
& L_{p}\left(p^{I}, t, \psi^{*}\right)=V_{p}\left(p^{I}, t, \psi^{*}\right) .
\end{aligned}
$$

The solution to the differential equation (13) is:

\footnotetext{
${ }^{31}$ Capital expenditures are treated as expensible for convenience.
} 


$$
\begin{aligned}
& L=a p^{b}, \\
& b=\frac{-\left(\tilde{\alpha}-\left(\sigma^{2} / 2\right)\right)+\left[\left(\tilde{\alpha}-\left(\sigma^{2} / 2\right)\right)^{2}+2 r \sigma^{2}\right]^{1 / 2}}{\sigma^{2}},
\end{aligned}
$$

with $a$ and $p^{I}$ determined by the necessary conditions (14) and (15).

To solve this system in the full-refunds case, substitute (16) into (14) and (15), solve (15) for $a$, and substitute the result into (14) along with eq. (10) for $V^{\mathrm{F}}\left(p_{0}, t ; \psi\right)$ to obtain:

$$
\begin{aligned}
0= & \frac{b-1}{b} p^{I} \bar{q} \int_{0}^{T}\left\{(1-\tau)+0.5 \tau\left[\Phi\left(d_{1}^{*}\right)-\beta \Phi\left(\hat{d}_{1}^{*}\right)\right]\right\} \mathrm{e}^{-\mu t} \mathrm{~d} t \\
& -c \bar{q} \int_{0}^{T}\left\{(1-\tau)+0.5 \tau\left[\Phi\left(d_{2}^{*}\right)-\Phi\left(\hat{d}_{2}^{*}\right)\right]\right\} \mathrm{e}^{-r t} \mathrm{~d} t-(1-\tau) I,
\end{aligned}
$$

with $d_{i}^{*}$ and $\hat{d}_{i}^{*}(i \in[1,2])$ evaluated at $p^{I}$. This equation implicitly defines the critical value $p^{I}$ above which the firm invests immediately. ${ }^{32}$

As discussed in section 2, the critical investment price depends on two factors. First, the value of a producing mine, $V$, must be greater than the investment cost, $I$. However, a positive net present value is not sufficient; we must also account for the value of waiting. The output price is stochastic so there is some probability that production will be worth more if commencement is delayed because the reserves sold today might receive a significantly higher price tomorrow. The value of waiting is the value of betting that the return from holding the asset in the ground another period will exceed the alternative return on current revenues.

The effects of the tax policies can be determined by implicitly differentiating (18). The expressions are quite messy but are straightforward to obtain, so I discuss the main results without presenting all of the calculations. ${ }^{33}$ Results 4 and 5 hold for both the full-refunds and no-refunds cases.

Result 4. Increasing the rate of corporate income taxation, $\tau$, can encourage investment, by lowering the optimal critical investment price, $p^{I}$.

\footnotetext{
${ }^{32}$ The same procedure yields an implicit solution when tax losses are not refunded, using eq. (9) for $V(\cdot)$.

${ }^{33}$ The details can be found in MacKie-Mason (1986).
} 
Result 5. Increasing the rate of the percentage depletion deduction, $\delta$, can discourage investment.

By 'discourage' investment I mean that a higher critical price must be reached for investment to take place. One might prefer to view this as delaying, rather than discouraging investment. However, with an increase in $p^{I}$ the probability that investment will have occurred by any date $t^{*}$ will decrease. Thus, for a portfolio of possible projects the aggregate amount of investment by $t^{*}$ will (in expectation) be lower. It is in this sense that investment is discouraged.

Increasing the corporate tax rate can encourage investment by changing the government's share of project risk. To understand this, note that the value of waiting to invest is quite similar to a financial call option. The firm can pay the investment costs $I$ to purchase an asset worth $V$ today. Or, the firm might wait to exercise the investment option because it can then gain the benefits if $V$ increases without paying the cost if $V$ decreases. Because of the asymmetric (convex) payoffs the value of a call option increases as risk increases. The government takes a share of the risky payoffs through the corporate tax; raising the corporate tax rate increases the government's share of the value of waiting, thereby reducing the firm's willingness to wait.

Of course, increasing the corporate tax rate also raises the cost of investment because the higher tax bills are incurred immediately rather than deferred. The net result is that an increase in the corporate tax rate encourages investment when the value of waiting is reduced by more than is the value of immediate investment.

Intuition can be strengthened by studying how the comparative static result depends on the parameters of the problem. In the full-refunds case higher $\tau$ will encourage investment ( $p^{I}$ falls) if

$$
\int_{0}^{T} \frac{1}{b} p^{I} \bar{q} \mathrm{e}^{-\mu t} \mathrm{~d} t>\int_{0}^{T}\left[p^{I} \mathrm{e}^{-\mu t}-c \mathrm{e}^{-r t}\right] \bar{q} \mathrm{~d} t-I .
$$

The right-hand side of (18) is the risk-adjusted present value of pre-tax net income if investment occurs now. The left-hand side is related to the value of waiting. ${ }^{34}$ From eq. (17) we see that as $\sigma^{2} \rightarrow \infty, b$ decreases with a limit of unity so the value of waiting dominates the value of immediate production.

\footnotetext{
${ }^{34}$ Letting the implicit function for $p^{I}$ in eq. (18) be called $\Psi$, implicit differentiation implies that $\mathrm{d} p^{I} / \mathrm{d} \tau=-(\partial \Psi / \partial \tau) /\left(\partial \Psi / \partial p^{I}\right)$. It can be shown that the denominator is positive and that expression (19) determines the sign of $-\partial \Psi / \partial \tau$.
} 


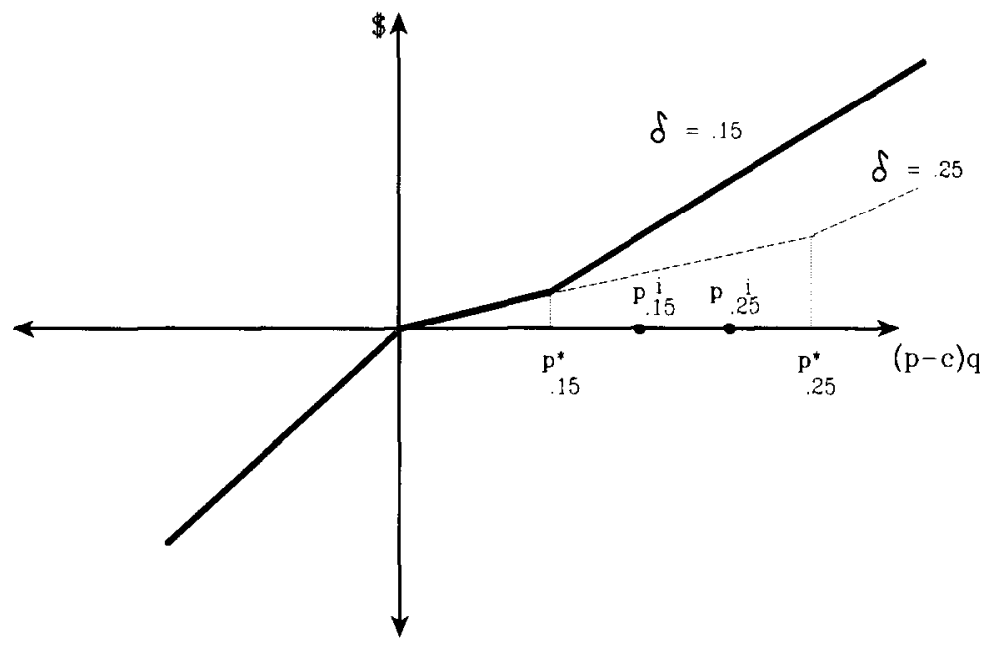

Fig. 3. An increase in the PDA can discourage investment. Increasing the percentage depletion allowance rate from 0.15 to 0.25 can raise the minimal price necessary to induce investment, $p^{i}$.

As risk increases the upper-tail payoffs increase but the lower-tail payoffs are unchanged, ${ }^{35}$ so the firm gets a large return from waiting. Likewise, $\mathrm{d} b / \mathrm{d} \tilde{\alpha}<0$; as the risk-adjusted rate of price growth increases, the return to holding the resource in the ground increases.

A higher corporate tax rate can encourage investment by lowering $p^{I}$ [expression (19) will hold] if the unit profit margin at the critical price is relatively small (such as it is when the investment cost that must be recovered is small), and the price variance is large. Under these circumstances the value of waiting is due more to the contribution of risk than to the expected growth in price, $\tilde{\alpha}$, and then the government's bigger risk share can reduce the value of waiting sufficiently to encourage immediate investment.

The importance of modeling uncertainty is evident from expression (19). With perfect foresight the inequality would never be satisfied (since $b \rightarrow \infty$ as $\sigma^{2} \rightarrow 0$ ) and a tax rate increase will always discourage investment. Thus, the interaction between the corporate tax rate and uncertainty can reverse the sign of the usual comparative static.

The PDA effect on the investment decision is similar to the effect of $\tau$, so I will describe it more briefly. The effect is illustrated in fig. 3. When the PDA rate is increased the kink in the tax function is moved outward (the higher $\delta$

\footnotetext{
${ }^{35}$ The payoffs are truncated below at zero because the firm is never obligated to exercise the investment option.
} 
means that price must be higher for the 50 percent of net income limitation to bind). Since the cream-skimming region has been shifted outward the firm will face the lower $\left(\tau_{2}^{*}<\tau_{3}^{*}\right)$ marginal tax rate on future income in more states of the world. That is, the government is reducing its share of the risk of waiting by reducing the convexity of its tax claim on stochastic cash flows. If the value of waiting is largely due to risk rather than expected price growth, then the government's reduced risk share will disproportionately increase the value of waiting relative to the value of immediate investment and thus investment will be discouraged.

The importance of nonlinearity for determining the tax effects can be further demonstrated by examining the interaction between the PDA and the corporate income tax rate. When tax losses are refunded the PDA rules provide the only nonlinearity in the tax system. Suppose $\delta=0$ so that taxes are linear: then taxes have no effect at all on investment. In eq. (18) we would have $\beta=1, d_{1}=\hat{d}_{1}$ and $d_{2}=\hat{d}_{2}$, so the factor $(1-\tau)$ divides out and $p^{I}$ is independent of $\tau$. Alternatively, if the kink were removed from the PDA, $\delta$ would be a simple severance subsidy on price and the income tax rate would still have no effect on investment. ${ }^{36}$ The distortionary effects of the cash-flow income tax are due entirely to the nonlinearity introduced by the PDA. ${ }^{37}$

These results clearly demonstrate the importance of interactions between tax nonlinearity and uncertainty. In both Results 4 and 5 the counterintuitive effects of changing the tax rates follow from changes in the government's risk share in the speculative value of waiting to invest. If either uncertainty or nonlinearity had been ignored the crucial effects would be missed.

\section{Numerical analysis}

In this section I numerically value an oil field, allowing for an initial investment decision and some output control after the project is developed. The numerical results confirm the economic intuition developed in section 3: although some investments are encouraged, the PDA can discourage other investments. The value of the PDA subsidy decreases with risk and the biggest subsidies are received by inframarginal projects. Thus, the analytical results hold under more realistic modeling assumptions. This section also

\footnotetext{
${ }^{36}$ A linear PDA subsidy rate will still affect investment because it differentiates between price and cost, which have different stochastic characteristics, and thus it distorts both the riskadjusted expected value of net income and the value of the waiting option.

${ }^{37}$ Lyon (1989) presents another example of tax system nonlinearity that can change the sign on investment incentives. He studies 'parallel' tax systems in which tax liability functions have kinks because of switches from one set of rules to another (e.g. an ordinary income tax and an alternative minimum tax). He finds that the cost of capital can increase or decrease, depending on the parameters of the problem. However, he does not consider uncertainty.
} 
Table 1

Assumptions for numerical valuations of oil field.

\begin{tabular}{ll}
\hline Costs & \\
Annual maintenance if closed & $\$ 5$ million \\
Unit cost of production & $\$ 3.51 / \mathrm{bbl}$ \\
Cost of opening or closing existing field & $\$ 1$ million \\
Initial investment cost & $\$ 500$ million \\
Taxes & \\
Corporate income tax rate & $50 \%$ \\
Percentage depletion allowance rate & varies \\
Tax treatment of losses & varies \\
Prices and production & $3 \%$ \\
Real interest rate & \\
Convenience yield ( $\mu=r-\tilde{\alpha})$ & varies \\
Instantaneous price variance & varies \\
Maximum reserves & 226.1 million bbl \\
Maximum annual extraction rate & 13.3 million bbl \\
\hline
\end{tabular}

serves to demonstrate the feasibility of numerical methods for evaluating nonlinear tax policies with uncertainty.

The assumptions about production, costs and rates of return are based on Lund's (1987) analysis of typical North Sea oil fields; see table $1 .{ }^{38}$ Field output is fixed if producing, but the firm may temporarily halt production if prices fall sufficiently and re-start if prices rise. Shutdown and reopening have a fixed cost. Maintaining a field during a dormant period has a flow cost. The firm can abandon a field permanently at zero fixed cost.

I present some representative results in tables 2, 3 and 4; table 2 assumes that loss offsets are immediate, and table 3 that tax losses are never refunded. Table 4 presents the value of the PDA subsidy for a few cases with full loss offsets. I consider several different combinations of the depletion allowance rate, the riskiness of the output price path, and the convenience yield on oil. $^{39}$

The numerical calculations confirm the earlier results. In table 2 the prices $p_{I}^{*}$ are the critical prices required for initial investment in the field. For all three combintions of risk and convenience yield presented, the minimal investment price decreases as the PDA rate increases; the PDA encourages these large investments.

However, at lower prices, when current production is marginally profitable, the PDA can discourage productive investments. For example, in most

\footnotetext{
${ }^{38}$ The investment cost I use is only $\$ 500$ million instead of the $\$ 700 \mathrm{MM}$ in Lund's paper because the optimal investment price was implausibly high for $\$ 700 \mathrm{MM}$. This is probably due to my assumption that the lease right lasts forever when in fact leases typically expire after a few years, thus lowering the return to waiting and encouraging investment at lower prices.

${ }^{39}$ The convenience yield is $\mu$ which determines the risk-adjusted rate of expected price growth, $\tilde{\alpha}=r-\mu$.
} 
Table 2

Asset values and investment decisions: Full loss offsets (field values in million \$).

\begin{tabular}{lcccrrr}
\hline PDA rate $(\delta)$ & $p_{I}^{*}$ & $V_{0}\left(p_{I}^{*}\right)$ & $p_{0}^{*}$ & $V_{\mathrm{c}}\left(p_{0}^{*}\right)$ & $p_{\mathrm{s}}^{*}$ & $V_{0}\left(p_{\mathrm{c}}^{*}\right)$ \\
\hline Case $1: \sigma^{2}=0.0685, \mu=0.04$ & & & & & & \\
$\quad 0 \%$ & 21.46 & 1460.6 & 3.83 & 70.2 & 2.62 & 13.4 \\
$15 \%$ & 18.92 & 1482.8 & 4.00 & 107.5 & 2.98 & 39.8 \\
$22 \%$ & 17.39 & 1435.6 & 4.17 & 130.5 & 3.11 & 52.5 \\
Case 2: $\sigma^{2}-0.137, \mu-0.04$ & & & & & & \\
$\quad 0 \%$ & 30.02 & 2179.7 & 4.73 & 158.5 & 3.24 & 68.1 \\
$15 \%$ & 26.47 & 2210.9 & 4.54 & 186.4 & 3.24 & 91.1 \\
$22 \%$ & 24.34 & 2146.0 & 4.73 & 218.4 & 3.38 & 109.4 \\
Case 3: $\sigma^{2}=0.137, \mu=0.08$ & & & & & & \\
$\quad 0 \%$ & 24.34 & 1225.2 & 3.68 & 42.3 & 2.22 & 2.5 \\
$15 \%$ & 21.46 & 1241.5 & 3.83 & 64.4 & 2.63 & 15.7 \\
$22 \%$ & 20.57 & 1263.2 & 3.83 & 70.0 & 2.63 & 17.6 \\
\hline
\end{tabular}

Notes: $\left(p_{i}^{*}, p_{0}^{*}, p_{\mathrm{c}}^{*}\right)$ are prices at which it is optimal to make the initial investment in the field, re-open a closed but developed field, or close an opcrating ficld, respectively. $V_{0}(\cdot)$ is the value of a developed field if open (operating); $V_{\mathrm{c}}(\cdot)$ is the value of a developed field which is not producing (shutdown).

Table 3

Asset values and investment decisions: No loss offsets (field values in million $\$)$.

\begin{tabular}{lcccccc}
\hline PDA rate $(\delta)$ & $p_{I}^{*}$ & $V_{\mathrm{o}}\left(p_{I}^{*}\right)$ & $p_{0}^{*}$ & $V_{\mathrm{c}}\left(p_{0}^{*}\right)$ & $p_{\mathrm{c}}^{*}$ & $V_{0}\left(p_{\mathrm{c}}^{*}\right)$ \\
\hline Case 1: $\sigma^{2}=0.0685, \mu=0.04$ & & & & & & \\
$0 \%$ & 21.46 & 1460.3 & 4.00 & 78.3 & 3.11 & 30.4 \\
$15 \%$ & 18.92 & 1482.8 & 4.17 & 119.1 & 3.38 & 62.4 \\
$22 \%$ & 17.39 & 1435.4 & 4.17 & 129.7 & 3.24 & 59.5 \\
Case 2: $\sigma^{2}=0.137, \mu=0.04$ & & & & & & \\
$0 \%$ & 30.02 & 2179.4 & 4.73 & 158.0 & 3.38 & 75.0 \\
$15 \%$ & 26.47 & 2210.5 & 4.73 & 201.1 & 3.53 & 109.6 \\
$22 \%$ & 24.34 & 2145.7 & 4.73 & 218.2 & 3.53 & 110.1 \\
\hline
\end{tabular}

Notes: See table 2.

cases an increase in the PDA leads to a higher required price before it is optimal to make the fixed cost investment in reopening a closed field $\left(p_{0}^{*}\right)$. Similarly, increases in the PDA increase the likelihood that firms will 'disinvest' ( $p_{\mathrm{c}}^{*}$ rises) by temporarily halting production of operating fields.

The results in table 4 demonstrate that much of the PDA subsidy consists of inframarginal rents. The PDA subsidy is calculated as the difference between field values with and without a PDA. When output price is $\$ 30$ per barrel the subsidy is $\$ 538$ million for a field with 'low costs'. The subsidy at a price of $\$ 3.53$ per barrel, essentially equal to marginal cost, is only $\$ 36$ million for a low-cost mine. Viewed another way, the subsidy at $\$ 30 / b$ bl for a 
Table 4

Value of the PDA subsidy (million \$).

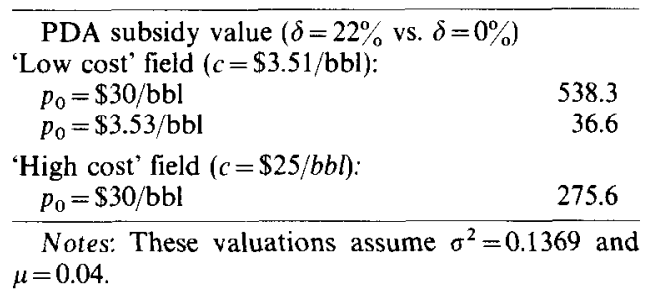

'high-cost' field (such as a tertiary-recovery field) is only \$276 million; about half the subsidy to a low-cost, inframarginal project.

\section{Conclusion}

In this paper I have analyzed the effects of a nonlinear tax rule on asset values and investment decisions when prices are uncertain. The main findings are surprising: the percentage depletion allowance subsidizes asset values but discourages some investments in mining projects and can encourage firms to shut down marginally profitable projects. Furthermore, despite proponents' arguments that the PDA is compensation for unusual risk, I demonstrated that under quite general conditions riskier projects receive smaller subsidies.

Another striking result concerns the importance of nonlinearity and uncertainty for the effects of the corporate income tax on investment decisions. A symmetric and linear tax without a PDA has no effect on investment. A corporate tax with a nonlinear PDA but no uncertainty reduces asset values and discourages investment. However, when uncertainty is introduced the corporate tax shares in the risky value of waiting and may actually encourage investment.

I used the stochastic equilibrium valuation method for studying tax effects with nonlinearity and uncertainty. Special cases of the method have been used recently for specific tax problems but I present a general statement of the method which allows for a wide variety of tax rules, investment decisions and dynamic operating control decisions. The method is feasible for analytical and numerical evaluation of tax effects on asset values and investment decisions. Given the evident importance of interactions between nonlinearities and uncertainty, the valuation method should receive wide use in a number of tax applications.

I examined a specific tax rule for mining firms, but many of the conclusions are quite general. The effects of the depletion allowance and the corporate income tax on investment decisions were due to changes in the government's share in the risk associated with delaying investment. Changes 
in risk share can occur with many different tax rule changes. To correctly evaluate both the magnitude and the direction of tax effects it may be esential to carefully model interactions between nonlinearity and uncertainty.

\section{References}

Auerbach, A.J., 1986, The dynamic effects of tax law asymmetries, Review of Economic Studies LIII, 205-226.

Ball, R. and J. Bowers, 1983, Distortions created by taxes which are options on value creation: The Australian resources rert tax proposal, Australian Journal of Management 8, 1-14.

Brennan, M.J. and E.S. Schwartz, 1978, Finite difference methods and jump processes arising in the pricing of contingent claims: A synthesis, Journal of Financial and Quantitative Analysis, 461-474.

Brennan, M.J. and E.S. Schwartz, 1986, Evaluating natural resource investments, Journal of Business 58, 135-157.

Bulow, J. and L.H. Summers, 1984, The taxation of risky assets, Journal of Political Economy $92,20-39$.

Clark T.B., 1985, Retreating to tax reform, National Journal 1267, 1298-1312.

Constantinides, G.M., 1978, Market risk adjustment in project valuation, Journal of Finance 33, 603-616.

Cox, J. and S. Ross, 1976, The valuation of options for alternative stochastic processes, Journal of Financial Economics 3, 145-166.

Domar, E.D. and R. Musgrave, 1944, Proportional income taxation and risk taking, Quarterly Journal of Economics, LVIII, 382-422.

Edwards, J. and C. Mayer, 1983, Leasing and the cost of capital, Mimeo. (Oxford).

Geske, R. and K. Shastri, 1985, Valuation by approximation: A comparison of alternative option valuation techniques, Journal of Financial and Quantitative Analysis 20, 45-71.

Glen, M., 1985, Heavy lobbying and partisan politicking may save oil industry tax preferences, National Journal, 1008-1012.

Gordon, R., 1985, Taxation of corporate capital income: Tax revenues versus tax distortions, Quarterly Journal of Economics 100, 1-27.

Gordon, R. and J.D. Wilson, 1989, Measuring the efficiency cost of taxing risky capital income, American Economic Review 79, 427-439.

Hausman, J.A., 1981, Labor supply, in: H.J. Aaron and J.A. Pechman, eds., How taxes affect economic behavior (Brookings, Washington, DC).

Lund, D., 1987, Investment, taxes, and uncertainty, with applications to the Norwegian petroleum sector, Memorandum no. 1 (Department of Economics, University of Oslo, Norway).

Lyon, A.B., 1989, Understanding investment incentives under parallel tax systems: An application to the alternative minimum tax, Working paper 89-93 (University of Maryland).

MacKie-Mason, J., 1984, Effects of federal tax policy on optimal consumption and exploration plans for exhaustible natural resources, Working paper.

MacKie-Mason, J.K., 1986, Nonlinear tax policies and the risk-taking behavior of firms, Chapter 1, Ph. D. dissertation (MIT).

MacKie-Mason, J., 1987, Long-term contracts and sequential economic decisions, Working paper (University of Michigan).

Majd, S. and S.C. Myers, 1985, Valuing the government's tax claim on risky assets, NBER Working paper no. 1553.

Majd, S. and S. Myers, 1986, Tax asymmetries and corporate income tax reform, NBER Working paper no. 1924.

Mayer, C., 1986, Corporation finance, tax, and the cost of capital, Review of Economic Studies LIII, 93-112.

McDonald, R. and D. Siegel, 1984, Option pricing when the underlying asset earns a belownormal equilibrium rate of return, Journal of Finance 39, 261-266.

McDonald, R. and D. Siegel, 1986, The value of waiting to invest, Quarterly Inurnal of Economics, CI, 707-727. 
Merton, R.C., 1973a, An intertemporal CAPM, Econometrica 41, 867-887.

Merton, R.C., 1973b, Theory of rational option pricing, Bell Journal of Economics 4, 141-183.

Merton, R.C., 1981, On the mathematics and economic assumptions of continuous time models, in: W.F. Sharpe, ed., Financial economics: Essays in honour of Paul Cootner (Prentice-Hall, Englewood Cliffs, NJ).

Paddock, J., D. Siegel and J. Smith, 1988, Option valuation of claims on real assets: The case of offshore petroleum leases, Quarterly Journal of Economics CIII, 479-508.

Pindyck, R., 1988, Irreversible investment, capacity choice and the value of the firm, American Economic Review 78, 969-985.

Rothschild, M. and J.E. Stiglitz, 1979, Increasing risk I: A definition, Journal of Economic Theory 2, 225-243.

Smith, C.W., 1976, Option pricing: A review, Journal of Financial Economics 3, 3-51. 